\title{
한국의 개발경험 공유
}

이 일 청 (UNRISD 연구조정관)

\section{목 차}

1. 배경

가. 한국의 개발경험에 대한 설명들

나. 개발전략의 내재적 요소로서의 사회정책

다. 사회정책의 정치학

라. 개발 맥락에서의 권위주의와 민주주의

마. 산업정책과 사회정책

바. 국제적 맥락 : 국제 원조, 지식 전파, 그리고

국가적 소유 기업 (nationally owned enterprises)

사. 농어촌 개발

아. 개발의 이면

자. 한국의 경험으로부터 배운다는 것

2. 맺음말을 대신하여

\section{1. 배경}

한국이 1945 년 일본으로부터 해방되었을 때, 한국은 식량 자급 조차 달성하지 못하고 거액 의 원조에 의존하는 농업경제국이었다. 불안정한 정치는 소비에트 러시아의 지원을 받는 북한 과 미국의 경제적인 지원을 받는 남한간의 한국전쟁을 유발했고, 이로인해 극심한 빈곤과 불 
평등이 만연했다. 미국은 1945년부터 한국에 상당한 원조를 제공했고, 한국은 1970년대까지 미국의 우선 원조대상국이었다. 1945년부터 1965년 사이 미국의 원조 대다수는 주로 식품과 비료였다. 원조 총액 중 무상원조 요소는 1960년대 중반부터 상당히 떨어졌다. 그러나 1965년 부터 1989년까지 무상원조 요소가 급격하게 떨어졌음에도 불구하고, 1 인당 연평균 GDP는 $7.2 \%$ 로 증가하였고, 소득격차와 빈곤 수준은 중위소득국가보다 더 나아졌다. 한국이 받는 원 조비율은 1960년대 GNP 9.3\%에서 1980년대에는 0.6\%로 점차 줄어들었고 1995년에는 세계 은행의 원조국가 리스트에서 이름을 지웠다. 어떻게 전쟁과 분단의 아픔을 겪은 원조의존국가 가 “한강의 기적”을 이뤄냈으며, 그 짧은 시간에 “한국전쟁의 파괴와 잔해로부터 불사조처럼 다시 일어날 수 있었을까?” (Wornonoff, 1983; Koen, 1977) 이와 같은 경험에서 얻는 교훈은 무엇일까?

국제개발협력의 성과가 그리 만족스럽지 않았기 때문에 한국의 경험으로부터 얻을 수 있는 교훈에 대해 관심이 점차 높아지고 있다. 경제적, 사회적 발전에 상당한 성과를 보이고 있는 아시아 신흥 산업국가들과 최근 부상하고 있는 신흥 성장국과 함께, 한국의 경험은 20 세기와 21 세기의 다양한 도전들에 직면해 있는 개발도상국들에게 새로운 롤 모델로 여겨지고 있다. 한편, 한국과 신흥성장국들이 국제개발의 새로운 행위자로 국제사회에서 정치적, 경제적 영향 력을 높이면서 선진국과 개발도상국 모두와 그 발전경험을 공유하려는 노력을 배가하고 있다. 이러한 변화는 G20, OECD 개발원조국 위원회, 그리고 UNDP 등 주요한 국제적 무대와 기관 에서 여실히 드러나고 있다

이러한 상황에서, 유엔 사회개발 연구소(UNRISD)와 한국국제협력단(KOICA)은 한국의 개 발경험으로부터의 교훈을 도출하고 공유하기 위해 "Making Development Cooperation Effective : Learning from South Korean Experience” 라는 공동 연구 프로젝트를 2011년부 터 진행하였다. 한국과 외국의 정치학, 국제정치학, 경제학, 사회학 등 다양한 분야의 전문가 10 여명 이상이 이 프로젝트에 참여하였다. 본고는 이 프로젝트의 일환으로 수행된 각종 연구 작업의 성과인 논문들의 첫번째 정리이다.

\section{가. 한국의 개발경험에 대한 설명들}

한국의 경제 사회적 발전의 성공, 특히 1960 년대 이후 30 년간 빠른 산업화를 이룬 점에 대 한 설명은 그 초점과 강조에 있어 견해가 다양하다. 경제 성장, 특히 산업화에 초점을 맞춘 연 
구는 세가지 접근법이 있다. 첫째, 시장 순응적(market conformist) 접근은 자유시장질서에 순응하는 제도와 정책을 만든 국가의 역할을 강조한다(The World Bank, 1993; Little, 1982; Krueger, 1990; Balassa, 1991). 둘째, 발전지향적 국가(developmental state)적 접근은 개 발의 비전과 헌신을 가진 정치적 리더쉽, 효율적이고 능률적인 관료제, 정부 통제하의 금융제 도, 경제개발 계획을 위해 시장 질서를 목적에 맞게 형성한 정부와 수출지향적 대기업간의 산 업 동맹 등, 각종 제도(institutions)의 역할에 주목한다(Wade, 1990; Kim, 1997; Johnson, 1987; Amsden, 1992). 셋째, 국제관계를 중시하는 접근은 한국이 가진 식민지 시절의 유제 나, 세계 생산 시스템 속에서 한국의 위치 등을 중심으로 한국의 경험을 설명하고 있다 (Cumings 1987; Kohli 2004).

주목하고 강조하는 측면의 다양성에도 불구하고, 이런 접근법들의 몇가지 공통점이 있다. 첫째, 그것이 시장 순응형이건, 아니면 국내, 혹은 세계시장 질서를 목적에 맞게 변형시키는 것이건, 정부의 강력한 역할이 강조되고 있다. 둘째, 몇몇 연구를 제외하고는, 한국이 권위주 의 정부하에서 집중적인 산업화를 이뤄낸 1960년대 이후의 시기에 주목하고 있다. 한국의 경 우 제도적 연속성보다는 단절성이 이론적 시사점으로써 강조되어왔다. 여기에서 연속성은 유 교를 촉진시키고, 성과중심주의사회, 중앙집권화되고 과대성장한 국가와 같은 전통과 문화의 애매한 개념들과 관련된다. 셋째, 발전지향적 국가론자들이 강조해왔던 효율적이고, 효과적이 며 역량있는 관료제가 한국의 산업화 성공의 중심적 요소로 광범위하게 분석되었다. 그러나, 이러한 분석들의 대부분은 무엇이 1960 년대 이후에만 관료제가 이처럼 효율적이고, 효과적이 며 역량있게 되었는가에 대한 원인에 대해서 문제제기를 하지 않았다는 공통점이 있다. 마지 막으로, 대부분의 연구들은 사회개발을 경제성장으로 인한 자연스런 결과물로 간주하였다. 그 러므로, 한국의 사회개발에 대한 설명에 있어 빈곤과 불평등을 축소하고 사람들의 능력을 보 다 더 확장하기 위한 목적있는 정책과정과 집중성은 그리 부각되지 못하였다(Deyo, 1987). 이 점을 특히 주목해야 하는데, 바로 이러한 점이 한국의 경험이 개발이론 정립에 충분히 기여하 지 못하도록 작용하기 때문이다.

한국의 경제개발의 사회정치적 측면은 한국의 개발 과정의 형성과 본질을 구성하는 제도와 행위자들간의 상호작용을 보여주는 중요한 영역임에도 개발의 이론적 논의 과정에서 소외되어 왔다.

이런면에서, 한국을 포함한 동아시아의 사회정책의 본질과 역할의 연구는 경제정책 중심의 한국개발 이해를 보완함으로써 중요한 기여를 하였다. 사회정책 연구의 결과는 다양하지만, 크게 두가지 연구 경향으로 나누어 볼 수 있을 것 같다. 복지국가의 부정적인 면을 강조하는 
구조조정 시기에, 세계은행과 같은 영향력 있는 국제개발기구들은 동아시아, 특히 한국의 사 회 정책이 시장을 보완하는 교정 메커니즘의 역할만을 수행했다고 주장했다. 이러한 주장의 근저에는 시장 친화적 정책, 특히 정부 예산 중 낮은 수준의 복지 지출이 높은 경제 성장율과 낮은 불평등과 밀접히 관련되어 있다는 주장이 자리하고 있었다. 한국과 다른 아시아의 산업 국들이 이러한 주장을 뒷받침하는 사례로 제시되었고, 이는 선진국과 개발도상국 모두에서 복 지국가의 축소를 주장하는 이들에게 근거로 제시되기도 하였다(Goodman et al, 1998). 이렇 게 한국은 “사회정책 비존재 지역 (social policy free zone)" 으로 보이게 되었고, 결국은 급속 한 경제성장을 이루는 시기에도, 개발도상국에서 복지국가를 이루는 것은 가능하지 않다는 증 거로 제시되었던 것이다 (Chang 2004).

이와는 대조적으로, 또 다른 사회정책 연구 경향은 경제성장을 촉진시키는 사회정책의 역할 을 강조하고 있다. 경제 성장에 관한 발전지향적 국가 이론에 크게 영향을 받은 이 연구 경향 은 마치 고고학적 발굴을 하듯 사회보장정책의 예와 흔적들을 찾아냈다. 이 연구는 "유교적 가 족 복지 국가" (Jones, 1990), “생산적 복지국가” (Holiday, 2000), “발전지향적 복지국가” (Gough, 2001)등으로 이름 붙여지는 다양한 접근처럼 경제성장에 사회정책이 어떤 도구적 역할을 하였 는가를 분석한다. 이러한 접근들 역시 몇가지 특징을 공유하고 있다. 첫째, 그들은 건강 보험, 연금 등 유럽의 컨텍스트에서 전형적인 사회 보장 제도로 간주되는 사회 정책 프로그램에 초 점을 맞추고 있다. 둘째, 복지 제공자에 대한 강조의 정도가 다양하지만, 대부분의 경우 관리 통제자(regulator)로서의 국가의 역할을 강조한다. 셋째, 사회정책과 경제정책, 특히 다양한 수준과 각종 단위에 있어서의 산업정책과의 관련성을 강조한다. 사회정책, 특히 교육정책의 역할은 인적 자본을 축적하는 중요한 시스템으로, 사회보험은 산업화의 재원을 조달하는 체계 로 강조된다. 경제개발을 위한 사회정책의 이러한 도구성은 적어도 아시아 경제위기까지는 사 회정책이 경제 정책과 성장에 종속되어있었다는 것의 근거가 되기도 한다(Kwon, 2005).

이 모든 연구성과에도 불구하고, 한국의 개발을 온전히 이해하기 위해서 해명되어야 할 이 론적·경험적 이슈들이 남아 있다. 첫째, Esteves-Abe가 지적하고 있듯이, 여러가지 형태로 사회정책의 역할을 했던 기능적 등가물(functional equivalents), 특히 본격적인 산업화가 이 루어지기 전인 1950년대에 존재했던 기능적 등가물에 대해서 완벽한 조사가 이루어지지 않았 다(Estevez-Abe, 2008). 최근의 연구에 의해서 부각되기 시작한 토지개혁 등과 같은 기능적 등가정책(Kwon and Yi, 2010), 그리고 그 정책의 영향, 과정, 제도, 그리고 주요 행위자 및 복지 효과 등은 충분히 설명되어야 할 과제로 남아있다. 둘째, 어떤 제도가 자원을 상품과 서 비스로 변환시키는데 영향을 끼치는가에 대한 깊은 이해를 위해, 내생적 성장 이론과 같은 성 
장에 관한 제도주의적 경제학 이론들이 기여해 왔다는 것은 널리 알려져 있다. 사회정책, 특히 교육과 보건정책은 자원이 상품과 서비스로 전환하는데 큰 역할을 해 온 것이다. 한국 역시 이 러한 설명의 예외가 아니다. 그러나 코스타리카, 쿠바, 방글라데시처럼 상대적으로 높은 개발 지수, 그렇지만 낮은 경제 성장을 보인 몇몇 국가들에서 알수 있는 것처럼, 인간 역량(human capability)을 제고시킨 제도들이 반드시 빠른 경제성장, 혹은 사회발전과 동일한 정도의 경제 성장 정도를 성취하는 것은 아니다. 역량 강화의 다양한 경로가 경제성장에 어떻게 영향을 끼 치는지를 설명하는 중범위 이론이 필요한 것이다. 셋째, 국제 생산 무역 시스템에서 한 국가의 위치는 그 국가가 생산과 무역에서 어떠한 정책을 선택하는가를 결정하는 중요한 변수라고 할 수 있다. 그러나 개발에 영향을 끼치는 이 변수는 생산과 교역에서의 위치 뿐만 아니라 안보관 계에서의 위치에 의해서도 결정된다. 특히 냉전시기 공산주의 블록에 대한 방어벽으로써의 역 할을 수행한 한국의 경우, 이러한 안보관계에서의 위치는 개발과 관련하여 명확하게 설명되어 야 한다. 넷째, 앞의 지적과 관련하여, 한국에 대한 외국으로부터의 원조는 경제성장과 사회발 전, 특히 이승만 정부 시기(1948-1960), 박정희 정부 시기(1961-1979) 의 경제성장과 사회발 전에 긍정적인 역할을 한 것으로 알려져 있다(Fritz and Menocal, 2007; Krueger, 1982; Krueger et al., 1989; Robert Cassen and Associates, 1994). 그러나 현재까지, 외국으로부 터의 원조에 대한 연구는 경제성장과 관련하여 역사적 사후 평가에 주로 의존해 있고, 원조의 내용과 원조국의 역할이 이들 다른 정권에 어떤 영향을 끼쳤는지는 충분히 설명되지 못했다. 마지막으로, 한국 개발의 이면, 즉 한국 개발 성공의 부정적인 측면에 대한 설명은 거의 그 자 리를 찾지 못했다. 이상에서 지적한 많은 한계와 문제점들을 해결하기 위해서는 분석의 범위 를 더욱 확대해, 제도, 과정, 행위자, 경제 및 사회 발전의 다양한 영향을 포괄하여 연구할 필 요가 있다. 이것이 유엔사회개발연구소와 한국국제협력단의 공동 연구 프로젝트가 지향하는 바였다.

\section{나. 개발전략의 내재적 요소로서의 사회정책}

사회보장(social security), 복지국가(welfare state), 복지 정책(welfare policy), 사회보호 (social protection) 등 다양한 용어로 표현되는 사회정책은 지금은 이미 선진국이 된 “후발 산 업국의 개발정책(the development strategies of late-industrialisers)"의 내재적 요소였다. 북반구(Global North)의 국가들이 급속한 개발을 이루고 있을때, 이 국가들은 국민소득이 상 대적으로 낮은 수준이었음에도 불구하고 인구의 대부분을 그 대상으로 하는 많은 사회정책을 시행하였다. 이 정책들은 사회변화로 인해 생긴 비용과 이익들을 재분배하고, 실업과 같이 사 
회변화로 인해 생긴 비용을 사회적으로 지불하는 정책이었다. 이러한 사회변화로 인한 비용을 지불하는 적절한 사회정책이 없이는 지속가능한 경제 발전이 어렵고, 이러한 사회정책을 지탱 하는 물적 재원 없이는 사회적 비용을 지불하는 정책 역시 지속가능하지 않았다. 이런 의미에 서 사회정책은 단지 빈곤 계층에게 잔여적 사회 안전망(residual social safety net)을 제공하 는 것에 그치지 않았다. 사회정책은 사회적 비용을 줄이고 지불하기 위한 예방적, 보상적 역할 을 수행해야 했다. 그러므로 사회정책은 개발과정 그 자체의 내재적 요소였던 것이다.

그러나 1970년 이후, 개발의 주류 이데올로기와 정책들은 사회정책을 자유 시장 질서를 보충 하기 위한 잔여적이고 사후적인 정책으로 간주하기 시작했다. 특히 신자유주의적 사고와 정책 이 개발 분야에서 지배적인 위치를 점하기 시작한 1980년대 이후로는 사회정책의 생산적 측면, 생산과의 연계에 대한 관심이 점차 사라지기 시작했다. 이러한 경향은 빈곤축소전략(PRSP)이 나 새천년개발계획(MDG)가 근거하고 있는 논리에서 잘 드러나고 있다. 두 정책 모두에서, 산 업정책과의 연계 혹은 사회정책 그 자체로 직업을 창출하는 사회정책의 역할은 주변화되고, 빈 곤을 감소하는 사회정책의 역할만이 특화되고 있다(Fine, 2011). 이 맥락 속에서 사회정책은 개인적 위험 혹은 취약성의 결과에 대응하는 정책이지, 직업을 창출하고 물적 재원을 생산해내 는 정책의 중심요소가 아닌 것이다. 즉 사회정책은 빈곤의 구조적 요인을 해소하는 정책으로 자리매김 하지 못한 것이다. 새천년개발계획에서의 불평등에 대한 상대적 무관심은 개인적 위 험과 취약성 해소에 초점을 맞추는 사회정책의 협소한 해석과 부분적으로 관련이 있다고 할 수 있다.

Thandika Mkandawire가 이 프로젝트를 위해 쓴 논문(Lessons from the Social Policy and Development of South Korea: An Interrogation)은 한국의 반세기에 걸친 사회정책 경험을 검토하여 현재의 개발도상국을 위한 교훈을 찾아내려는 시도를 보여주고 있다. 논문은 목적의식적으로 추구된 사회정책뿐만 아니라, 의도되지는 않았지만 사회경제적 개발 결과를 낳은 사회정책적 요소까지 포함한 광의의 사회정책을 검토하였다. 사회정책을 이런 방법으로 바라봄으로써, 저자는 과거로부터 배울때 주의해야할 것 역시 지적하고 있다. 그는 "문화적 편 견”, “헤게모니로부터의 외압”, 후발주자들의 “배울 수 있는 능력의 한계”, 선발주자들의 자신 의 역사에 대한 왜곡 혹은 망각 등을 역사적 교훈의 현대적 적용을 가로막는 장애물들 중 하나 로 지적하고 있는데, 이는 바로 이 프로젝트 자체가 한국의 개발 경험 연구를 통해 지적하고 바로잡으려는 문제점들이라 할 수 있겠다. 한국에서의 사회정책 검토를 통해, 그는 초기 조건, 이데올로기적 조건, 임금 협상 조건 혹은 분배의 조건, 경제 구조, 재정적 조건, 투자 조건, 노 동 시장 조건, 기술 조건, 그리고 국제적 조건 등에서의 성공과 실패를 가름하는 요소들을 제 
시하고 있다.

이 프로젝트에서 Peter Evans는 한국개발을 이용하는데 많이 사용되고 있는 경제개발의 축 적 패러다임에 대한 비판을 담당하였다. 그의 논문(The Korean Experiences and the $21^{\text {st }}$ Century Transitiontoa Capability Enhancing Developmental State)은 이미 많은 규범 적, 이론적, 경험적 연구들이 A. Sen의 역량 강화 개념에 기반한 개발에 대한 패러다임을 구축 할 수 있는 충분한 가능성을 보여주었다는 것을 재각인시켜준다(Sen, 1999). 물론 이러한 패러 다임이 구축되기 위해서는 분야별로 국한되는 개발의 성과(culminated outcomes)가 아니라 정책의 질과 규모, 정책 수행 주체, 정책 수행 과정 그 자체의 발전을 포함하는 포괄적 성과 (comprehensive outcomes)에 관심을 기울여야 한다는 것은 주지의 사실이다(Sen, 2010).

Peter Evans는 이러한 포괄적 개발결과에 초점을 맞추는 역량 강화 중심의 개발 패러다임 은 21 세기 사회, 경제, 정치적 조건에 더욱 중요하다고 주장한다. 이는 국제적, 국가적, 국가 내의 지방 레벨에서 공적, 사적 영역의 제도와 정책, 특히 사적영역의 시민사회 제도와 정책들 이 더욱 큰 영향력을 갖게 되고, 서로 간의 연계가 더욱 강화되기 때문이다. 이러한 새로운 시 각을 통해서, Peter Evans는 "만약 내적으로 일관되고 믿을 만한 패러다임이 출현한다면 그것 은 북구 선진국에서라기 보다는 넓게 정의되는 남반구의 개발도상국으로부터일 것이다.”라고 주장한다. 위의 남반구의 개발도상국에는 한국이 포함되어 있다. 그러나, 그는, 20 세기의 사 회변화를 위해 중심적 역할을 한 발전지향적 국가를 그대로 재주장하는 것만으로는 새로운 패 러다임을 구성할 수 없다고 주장한다. 경제성장의 역사적 경로를 검토한 후, 그는 21세기 사회 의 성공적 발전을 위해서는 20 세기 보다 국가의 역할이 더욱 중요하다는 것을 설명하면서, 21 세기의 발전지향적 국가의 주요 구성 요소는 개발성공을 위한 광범위한 국가-사회 관계의 상 향적 모델에서 찾아야 한다고 주장한다. 그는 한국을 비롯한 남반구의 성공적인 개발도상국들 의 발전 경로가 21 세기형 개발을 위한 교훈을 경제 - 사회정책과 관련된 역량강화의 관점에서 도출할 수 있는 좋은 사례들임을 밝히고 있다.

\section{다. 사회정책의 정치학}

사회정책은 권력과 자원의 분배를 내포함으로, 언제나 정치적 협상과 투쟁의 결과라고 할 수 있다. 정치적 요인, 제도, 과정은 사회정책의 본질과 그 결과에 큰 영향을 끼치는 것이다. 동아시아에서의 사회정책에 대한 연구는 사회정책, 특히 권위주의하의 사회정책의 형태와 내 
용을 결정하는 다양한 정치적 요소를 분석해왔다. 자신의 정당성을 강화하는 것은 권위주의 정부나 리더가 사회정책을 실시하는 중요한 정치적 요인중의 하나였다. 예를 들면 한국 복지 의 경우, 권위주의 정권의 정당성에 대한 추구가 사회정책 발전을 추동하는 중요한 정치적 요 소였던 것이다(Kwon, 1999). 싱가포르의 경우, 이러한 정당성의 추구는 성과의 추구로 나타 났다(Chua, 2005). 이러한 예들이 나타내고 있는 것은 다양한 권위주의 레짐이 선택한 사회 정책들을 구분하기 위한 중범위 이론의 필요성이다. 즉 권위주의의 어떤 측면이, 어느정도로 사회정책의 선택에 영향을 미쳤고, 그러한 정책의 개발 측면에서의 결과는 어떻게 달랐는가는 여러 권위주의 정권하에서 다양한 개발 경험을 가진 한국의 분석에 특히 중요한 문제라고 할 수 있다.

실제로 개발도상국에서의 사회정책은 다양한 이유에서 추구될 수 있다. 또한 그 사회정책들 은 시간, 장소, 조건에 따라서 빠른 경제성장을 낳을수도 그렇지 않을 수도 있다. 그러나 이러 한 관찰은 사회정책이 생산적 측면을 가지고 있지 않다는 것을 의미하는 것은 아니다. 오히려 이는 사회정책의 다양한 형태의 생산적 측면을 보여주는 것이다. 이 프로젝트의 이일청의 논 문("How Could Enhancement of Education and Health Contribution to Economic Growth in South Korea?”)은 특히 비슷한 물적 조건 속에서 정부의 상이한 정책 목표가 상이 한 정책 결과를 낳는 과정을 교육과 보건 정책의 검토를 통해 보여준다. 예를 들면, 초등, 중 등 교육의 팽창에 기여한 이승만 정부의 교육 정책은 그 목표가 실질적인 생산 기술 향상보다 는 반공주의, 국가 건설 등의 이념적 토대 구축과 관련된 것이었기 때문에 생산과의 연계가 미 약하였다. 반면, 박정희 정부는 기존의 교육정책을 바꾸면서, 교양교육 중심의 학교제도와 커 리큘럼을 직업, 기술 교육 중심의 체제로 바꾸려하였고 이는 결국 산업과 생산, 교육의 연계성 을 강화하는 결과를 낳았다. 사적 영역의 자원을 동원하고, 통제하며 공적영역과의 연계를 강 화하는 박정희 정부의 개발 전략과 계획 역시, 개발 결과에 있어서 이전 정부에 비해 큰 변화 를 가져왔다는 것이다.

필자, Olive Cocoman, 이현주, 정유아의 논문(Effective Aid and Development Cooperation in South Korea)은 이승만, 박정희 두 권위주의 정부의 외국 원조 자원의 동원, 할당, 사용에 초점을 맞추고 있다. 논문은 또한 각 정부가 원조공여국과의 관계에서 어떤 차이를 보이는지, 그리고 각 정부의 계획 역량과 협상 자본(negotiating capitals)에 어떤 상이점이 있는지 주목 하여 개발의 측면에서의 성공적 외자 동원과 사용을 설명하고 있다.

이와 관련해서 또한 질문되어야 할 것은 정책투입요소가 정책산출요소로 변환되어 나오는 과정에 대한 것이다. 이 프로젝트의 정무권의 논문(Development of Transformative Social 
Policy in Korea : Lessons from the Korean Experience)은 농업정책, 기술 정책, 직업 훈련 정책, 그리고 사회보험 정책에 초점을 맞추어, 주요 행위자, 정책 형성에 우호적인 환경, 그리 고 정책 투입요소의 산출로의 변환과정에서의 병목 현상 원인 등을 살펴보고 있다. 권위주의 정부들과 민주정부들의 복지와 관련된 정책을 검토하고, 사회정책 수행을 위한 다양한 행위자 를 동원하고 다양한 제도적 환경을 마련하였던 것이 사회, 경제적 전환의 요인이었다고 주장 한다. 특히 토지 개혁, 농업 보조금, 기술 형성 등의 사회정책적 등가물들은 전환적 요소를 지 니며, 이는 권력 관계와 사회적 구조를 바꾸기도 하였다는 것이다. 한 상황에서 전환을 추동했 던 환경이 다른 상황과 조건에서 지체의 원인이 되기도 한다. 저자는 이같은 예로, 1980년대 전두환 정부의 독일식 기술 형성 시스템의 도입 실패를 들고 있다. 즉 박정희 정부 하에 형성 된 노사관계, 고용주들간의 관계는 그 시기 엄청난 속도의 경제성장을 가능케 한 동력이었지 만, 전두환 정부 시절의 새로운 경제체제 전환을 기술 형성 시스템 도입에는 방해가 되는 요인 이었다는 것이다. 이는 어떤 제도들에 있어서 경로 의존성(path dependence) 또는 잔여력 (the staying power)이 행위자의 전략, 행동 패턴, 그리고 나아가서는 정책의 내용에도 큰 영 향을 끼친다는 것을 보여 준다. 즉, 기술 형성 시스템의 도입, 발전에 있어서 1960년대, 1970 년대에 발전을 가능케 했던 요인이 1980년대에는 발전을 방해하는 요인이 되었던 것이다.

정책 투입의 산출로의 전환과정과 관련하여 권위주의 정부가 사회적 이슈를 어떻게 문제화 하고, 이 문제를 다루는 사회정책을 어떻게 해석하였는가 역시 중요한 질문 중의 하나이다. 앞 에서 언급한 이일청의 논문이 보여주듯이, 교육의 경우, 일본 식민지 정권, 이승만 정부, 박정 희 정부 모두 교육의 사회적 영향, 그리고 그 목표에 있어서 상이한 인식을 하고 있었다. 세 정권 모두 교육을 위한 자원의 동원과 투자에 어느 정도의 노력을 기울이고 있었으나, 앞에서 언급한 차이가 각급 학교의 구성, 커리큐럼에서의 차이, 결과적으로 경제와의 관련성에서의 큰 차이를 낳는 원인 중의 하나가 되었다고 볼 수 있다.

\section{라. 개발 맥락에서의 권위주의와 민주주의}

한국 개발경험에 있어서 불편한 진실은 박정희 권위주의 정권하에서 실제로 급속한 경제성 장이 있었다는 것이다. 이러한 한국의 예는 실지로 많은 권위주의 정권의 지도자들이 자신의 정치적 정당성을 변호하는데 쓰이기도 하였다. 이러한 논의의 기원은 기실 제 2 차 세계대전 이

후로 거슬러 가서 찾을 수 있다. 아시아와 아프리카의 많은 국가들이 전후 독립하였을때, 민주 주의가 경제적 성장을 저해할 수 있다는 우려가 처음에는 미국에서, 곧 이어 자본주의 국가의 
많은 원조공여국들에서 점차 지배적인 생각으로 자리잡아갔다. 1970년대와 1980년대에 냉전 이 점차 본격화되어 가면서, 생각의 추는 반대방향으로 이동하게 되었다. 즉, 비록 레토릭에 지나지 않았을지 모르나, 자유 선거를 그 핵심으로 하는 자유 민주주의가 경제성장의 전제 조 건이라는 것이 그것이었다. 냉전 종식 후, 민주주의는 국제적 규범이 되었고, 원조 공여의 조 건이 되기도 했다. 사실, 권위주의, 민주주의, 그리고 성장의 관계에 대한 역사적 근거는 일관 되지 않다. 1950년대에, 터키, 코스타리카, 서독, 그리고 필리핀과 같은 권위주의 및 민주주의 레짐은 공히 빠른 경제성장률을 기록했다. 반면 1960년대와 1970년대의 경우, 가봉, 아이보리 코스트, 이라크, 요르단, 싱가포르, 몰타, 루마니아, 한국 등 모두 권위주의 정부를 가진 것으 로 분류되는 국가들이 빠른 경제 성장을 이루었다. 1980년대에도 지속적으로 경제성장을 이룬 국가들은 한국, 타이완, 싱가폴 등의 아시아의 신흥공업국들과 예멘 정도였고, 앞선 시기, 권 위주의 및 민주주의 레짐하에서 경제 기적을 이루었다고 일컬어지던 국가들은 모두 경제적으 로 파국을 맞았다. 1980 년대에도 지속적으로 경제성장을 계속한 국가들 중, 한국과 타이완은 1980년대 후반부터 민주화 도정에 들어서게 된다. 반면, 이라크, 아이보리 코스트, 나이지리 아, 수리남, 유고슬라비아 등 직전 10년 혹은 20 년동안 빠른 경제 성장을 보인 국가들은 심각 한 경제난을 겪고 있었다. 전쟁, 분쟁, 1 차 상품의 국제가격 변동성등이 이러한 경제난의 원인 으로 제시되고 있었다. 이같은 관찰은 정치체제와 경제성장간의 관계와 관련하여 한가지 주요 한 시사점을 내포하고 있다. 즉 빠르고 지속적인 경제성장이 권위주의 정권하에서 일어날 수 도 있으나, 경제적 파탄 역시 일어날 수 있다. 일군의 학자들은 민주주의와 권위주의의 차이가 경제성장과는 아무런 인과관계를 가질 수 없다는 메시지를 강조하면서 한국처럼 예외적일 수 있는 사례만을 보고 정치체제와 경제성장과의 관계를 해석하는 것은 무척이나 위험한 결론을 도출하는 것에 이를 수 있다고 경고한다(Przeworski et al., 2000). 이와 관련하여, 이 프로젝 트의 양재진의 논문(Change and Continuity in Social Policy Responses to Economic Crisis in South Korea : 1979-81)은 경제위기에 대한 권위주의 정권과 민주주의 정권의 상이한 대 응을 분석하고 한국의 사례가 권위주의가 민주주의에 비해 좋은 결과를 낳은 사례 역시 될 수 없음을 보여준다. 양재진은 경제위기에 대응하는데 있어서 권위주의와 민주주의의 진정한 차 이는 경제성장을 지속시키는 능력이 아니라, 각 정권이 가져오는 변화의 질적 차이라고 주장 한다. 1970년대 말부터 시작된 경제위기에 전두환 정부가 보여준 대응방식은 재정 긴축과 잔 여적, 기업 복지 중심의 복지 정책으로 비공식부분과 저임금 노동자를 배제하는 것을 그 특징 으로 하는 복지정책이었다. 이것은 1990년대 말의 김대중 정부가 1970 년대말과 1980년대 초 의 경제위기보다 더욱 심각한 경제위기를, 재정 확대와 그 대상의 폭과 깊이를 더욱 확대하는 포괄적 복지정책으로 돌파한 것과 큰 대비를 이룬다. 
1990년대의 경제위기에 대한 한국정부의 대응 정책과 관련하여, 기존의 연구중 하나는 "선 별적 발전지향적 복지국가”로부터 “포괄적 발전지향적 복지국가로의 전환”을 조심스럽게 예견 하기도 하였다(Kwon, 2005). 정부, 고용주, 노동조합의 협상의 결과, 고용보험과 같은 복지 프로그램의 실시와 확대가 이루어진 것이 이러한 낙관적 예상의 근거가 되었었다. 그러나 이 러한 협상의 결과 이루어진 복지제도의 성립과 확대는 그리 단순하지 않은 결과를 가져왔다. 앞에서 언급한 정무권의 논문은 명목적 사회보험 혜택 범위의 확대에도 불구하고, 실질적 혜 택은 그리 기대에 미치지 못하고 있다는 것을 보여준다. 건강보험과 산재보험을 제외하고, 대 부분의 복지 프로그램의 실질적 혜택은 명목상 복지 급여 수급이 가능한 이들의 절반 이하에 만 돌아가고 있다는 것이다. 이는 비공식 부분 노동자의 증가로 인한 것으로써, 경제 위기와 노동시장 유연화의 결과라고 보여진다.

사실, 한국의 권위주의 정권이 경제 성장에 있어서 경쟁력이 있었다는 것을 부인할 수는 없 다. 이는 아마 19 세기 비스마르크 치하의 프러시아나, 오늘날의 중국이나 베트남의 경우도 마 찬가지일 것이다. 그러나 이러한 사례들이 어떤 인과성을 증명하는 예가 될 수는 없다. 우리가 던져야 할 중요한 질문은 빠른 산업화와 경제성장을 이룬 것이 민주주의 체제인가 권위주의 체제인가의 문제가 아니라, 어떤 종류의 개발이 추구되었으며, 어떤 제도와 정책이, 그것이 권 위주의이건, 민주주의이건 간에, 정부가 개발 목표를 이루는데 도움이 되었는가와 관련된 것 이라 하겠다. 이러한 질문은 정치체제의 규범적, 실천적 차원에서의 중요성을 부정하는 것이 아니고, 오히려 개발적 맥락에서 민주주의와 권위주의의 이론을 정교화해야 한다는 요구를 담 고 있는 것이라 볼 수 있다.

\section{마. 산업정책과 사회정책}

숙련된 노동자의 제공, 그리고 사회정책으로 인해 조성된 재원의 투자재원으로의 활용 등과 같은 사회정책의 산업화 과정에서의 기여는 이미 많은 연구가 되어왔다. 사회정책과 산업정책 과의 관계는 사실, 교육되고 숙련된 노동자의 제공보다 더욱 복잡한데, 이는 사회정책 그 자체 가 때로는 고용을 창출하고, 수요 자체를 상승시키기도 하기 때문이다. 이러한 맥락에서, 산업 구조, 정책과 사회정책의 관례는 사회정책 연구 중 산업화 관점에서부터 최근의 복지레짐 접근 에 이르기까지 광범위하게 연구되어왔다(Esping-Andersen, 1990; Wilensky and Lebeaux, 1965). 
그러나, 그 자체가 산업정책의 중요한 결과물 중의 하나인, 특정의 산업구조, 기업 구조가 어떻게 사회 개발 혹은 사회 정책에 영향을 미치는가는 많은 연구가 되지 않았다(Mares, 2001). 이 프로젝트의 이주하의 논문(Institutional Linkages between Social Protection Measures and Industrialization in Korea)은 특정 산업 부분에 가능한 재원을 집중투자한 한국의 산업 정책이 한국 복지 제공의 특성, 즉 정부가 복지 재원을 제공하는데 작은 역할을 수행하는 특성을 구성하였다고 설명하고 있다. 즉 정부는 복지 재원 제공 대신, 경제·사회적 하부구조를 건설하고, 이를 통해 고용을 창출하는데 집중하였다는 것이다. 또한 정부는 조세 제도를 통해 노동 의욕을 고취시키고 노동자의 가처분 소득을 증대시켰다. 이주하의 논문은 진보적인 재분배정책과 다른 잔여적 재분배 프로그램의 선택은 노동자들, 특히 중소기업의 노 동자들의 소득을 증대시키는 정부의 산업, 임금 정책의 선택과 밀접한 관련이 있다고 주장한 다. 특히 경제 하부구조 건설, 교육과 직업 훈련 등의 사회적 투자, 재정, 조세 정책을 설명하 는 이주하의 논문은 생산, 재분배, 사회보장, 사회적 재생산의 연계에 있어서 한국만의 특징, 이름하여 한국적 전환적 사회정책의 특성을 보여주는데 기여하고 있다. 그는 이러한 방식의 복지 재원 동원과 복지 제공은 오직 지속적인 경제성장과 높은 고용률하에서만 가능하다고 지 적하고, 경제위기가 닥쳤을 때, 즉 기업의 투자 이익이 감소할 때에는 지속가능하지 않다는 것을 밝히고 있다. 아시아 경제 위기는 중요한 예라고 할 수 있다. 국가의 경제, 특히 재벌 경 제를 심대하게 훼손한 아시아 경제위기는 기업으로부터의 보수와 기업복지에 전적으로 의존하 고 있던 노동자들에게 막대한 고통을 초래했는데, 이는 삶의 수준을 보장할 수 있는 보다 체계 적인 복지 정책을 요구하는 것이었다.

\section{바. 국제적 맥락 : 국제 원조, 지식 전파, 그리고 국가적 소유 기업 (nationally owned enterprises)}

국제적 맥락은 한국의 개발을 설명하는 중요한 변수이다. 그러나 원조, 지식전파, 그리고 국가적 소유기업 등 국제적 맥락을 파악하는데 중요한 이들 이슈들은 국내적 변수에 대한 방 대한 양의 연구에 비해서 상대적으로 덜 연구되었다. 논쟁은 지금도 계속되고 있지만, 원조가 과연 경제성장에 긍정적 영향을 끼쳤는가에 대한 통계학적 근거는 그리 명확하지 않다 (Doucouliagos and Paldam, 2009). 회의적인 시각의 근거로 제시되는 것 중의 하나는 네델 란드 병(Dutch Disease) 효과라고 불리우는 것인데, 즉 원조의 유입이 자연자원으로 인한 수 입처럼 환율을 수출에 불리한 방향으로 움직여 결국 경제성장을 방해한다는 것이다(Raghuram and Subramanian, 2009). 이런 점에서 크게 원조에 의존하던 나라였던 한국의 성공은 국제 
개발원조의 역사에서도 매우 드문 경우 중의 하나라고 볼 수 있다. 한국이 원조를 받고 쓰던 상황과 지금 개발도상국이 처한 상황은 근본적으로 다르다고 할 수 있다. 냉전 종식 후, 이데 올로기적 이유로 부패하고 독재적 정부였음에도 불구하고 제공되던 원조 자금의 대부분은 사 라졌다. 민주주의가 국제적 규범이 되었고, 실지로 대부분의 개발도상국이 민주화의 도상에 있다고 볼 수 있다. 점차, 정치적으로 계몽된 대중이 정치 지도자들에게 경제·사회개발의 성 과들을 가시적으로 보여줄 것을 요구하고 있다. 물론 국가의 역량은 여전히 많은 한계를 가지 고 있고, 책무성 메카니즘 자체도 취약한 것이 사실이다(Fritz and Menocal, 2007).

이러한 상황에서, 1990 년대 이후, 국제개발협력계, 특히 주요 원조공여국과 공여기관에서 이론과 실천과 관련하여 두가지의 중요한 변화가 일어났다. 첫째는 경제·사회 개발에 있어서 의 좋은 제도(good institutions)와 좋은 거버넌스(good governance)의 중요성에 대한 재강 조이다(World Bank, 1997). 주요 원조기관은 원조의 조건으로 좋은 거버넌스를 제시하였다. 그 의미는 재정의 건전성만을 뜻하는 좁은 의미에서부터 민주주의와 효율적인 관료제를 의미 하는 넒은 의미까지 다양하였다. 빈곤국이 개발에 성공하기 위해서는 보다 효율적이고 효과적 인 정부와 거버넌스 시스템이 필요하다는 주장이 점차 더욱 많은 지지를 획득하고 있는 것이 다. 이러한 주장의 핵심적 근거 중의 하나가 동아시아 발전지향적 국가들의 개발성공사례, 특 히 한국의 사례이다. 한국이 원조 의존 국가에서 사회 경제 개발의 성공 사례로, 또한 차세대 원조공여국으로 부상하게 된 주요 원인 중, 특히 국제 원조 커뮤니티에서 중요하게 거론되는 것이 역량있는 정부의 존재였다. 이와 궤를 같이하는 것이 바로 역량있는 정부를 만드는 것을 도움으로써 수원국 중심의 개발, 즉 수원국 오너쉽을 진작시킬 수 있다는 원조효과성에 대한 파리 선언의 근간이 되는 주장이었다(Fritz and Menocal, 2007). 원조 시스템의 어떤 요소가 한국정부를 역량있는 정부로 만드는데 도움을 준 것일까? 아니면, 어떤 외부적 요소가 역량있 는 정부 형성에 도움을 준 것일까? 국내의 제도와 기구는 외적인 환경과 개입에 어떻게 반응 한 것일까?

앞에서 언급한 논문(Effective Aid and Development Cooperation in South Korea) 은 수 원국 중심의 개발을 가능케 한 국가 능력은 경제 계획과 외자와 내자를 동원하는 제도와 정책 이라고 설명하고 있다. 특히 이 논문은 이승만 정부와 박정희 정부의 차이를 원조를 포함한 외 자를 동원, 분배, 사용하는 정책과 제도, 특히 금융 산업과 경제 계획의 제도와 정책 부분에서 발견하고 있다. 1960 년대 초부터 시작된 경제개발 5 개년 계획은 경제와 사회개발의 중앙 조정 시스템으로써 특히 중요한 역할을 수행하였다. 경제개발 계획의 성공적인 실행은 정부 레벨에 서부터 민간 공장의 작업장에 이르기까지 침투되는 정부의 행정권력으로 인해 가능했는데, 
이는 공적 영역과 사적 영역의 기관이 동원됨으로써 가능했다고 설명된다.

프로젝트의 참가자 중 한사람인 Alice Amsdens은 논문(Securing the Home Market:A New Approach to Korean Development)에서 국가적으로 소유된 공적 사적 기업(nationally owned enterprises)을 보호하고 장려하는 다양한 메카니즘과 정책을 소개하고 있다. Alice Amsden은 특히 21세기 신자유주의 하에서의 산업정책의 역할에 주목하면서, 20세기와 21세 기의 산업 정책의 차이를 국가적으로 소유된 기업의 진흥책, 국내 시장의 보호와 장악, 고용 창출, 기술 수준 상승을 중심으로 한국, 브라질, 인디아, 중국, 타이완 등의 사례를 통해 살펴 보고 있다. 그녀는 2차 대전 이후 산업 정책의 근간, 특히 아시아와 아랍국가들의 산업 정책의 근간이 “재산 소유권의 왜곡(getting the property rights wrong)"과 관련이 있다고 주장한 다. 즉 식민지 권력으로부터 수탈한 재산권의 재편이 자국 소유 기업의 기반이 되었다는 것이 다. 다양한 역사적 예를 통해 어떻게 "재산 소유권이 개발을 위해 재편(making right the property rights for development)" 되었는가를 설명하면서, 그녀는 새로이 획득한 국가적으 로 소유된 재산을 잘 경영할 수 있는 기술을 가지는 것이 개발을 위한 중요한 조건이라고 주장 하고 있다. 특히 탈식민 국가와 개발도상국에서의 사적 영역의 취약성, 특히 100 에서 300 인 정도를 고용하는 중소기업군의 취약성을 고려할 때, 개발에 도움이 되지 않는 외국인 소유의 재산권이 아닌 개발에 도움이 되는 자국 소유의 재산권을 만드는 것이 특별히 중요하다고 주 장된다. Alice Amsden은 특히 어떻게 한국 정부가 크고 작은 자국 소유의 기업을 보호하고 장려하였는지에 대해 자세히 설명하고 있는데, 특히 1962년부터 1997년까지의 중소기업 장려 책을 자세히 설명하고 있다.

외국으로부터 지식과 기술을 어떻게 습득하는가는 수원국 책무성과 오너십의 미시적 기초 가 되는데, 이는 이러한 지식과 기술의 습득의 용이성이야말로 개발도상국이 선진국을 따라잡 는데 있어서(catching-up) 이점이 되기 때문이다. 이 프로젝트의 김태균의 논문(Learning through Localizing International Transfers: South Korea's Development Experiences) 은 지식과 기술을 흡수하는 능력과 관련된 국내적 조건, 그리고 산업과 노동력 구조의 전환 시 기에 있어서의 요소 이동성(factor mobility)은 전달된 지식과 기술의 효과성과 전파 스피드를 결정하는 요소라고 주장한다. 그는 인간의 역량, 특히 기술에 있어서의 인간의 역량을 강화하 는 국제적 요소들은 오직 국제적 요소가 전파, 흡수, 확산되는 것을 용이하게 하는 국내의 제 도적 장치가 완비되어 있을 때 그 효과가 극대화된다는 것을 주장한다. 산업정책, 특히 요소이 동성을 향상시키는 직업 교육은 경제 - 사회발전을 위한 지식과 기술 전파의 도구로써, 중요한 역할을 수행한다. 이러한 주장은 선진 해외기업과 이를 추격하는 자국기업간의 지식과 기술에 
있어서의 비대칭적 관계를 바로잡는 제도가 필요하다는 Alice Amsden의 주장과 그 맥을 같이 한다고 볼 수 있다.

프로젝트에 참가한 김은미의 논문(The South Korean Development Alliance)는 수원국 시 기의 한국, 공여국으로서의 한국이라는 두가지 관점에서 개발의 연대(development alliance) 의 의미와 내용을 살펴보고 있다. 한국의 개발과정에서 개발 연대가 어떻게 변화해왔는가를 살펴보고, 김은미는 20 세기의 개발 연대의 교훈은 국제 개발협력, 특히 글로벌 레벨에서의 개 발연대를 형성하기 위한 교훈으로 적극 활용되어야 한다고 주장하고, 한국이 21 세기에 원조공 여국으로서 지향해야할 개발연대에 대해서 설명하고 있다.

\section{사. 농어촌 개발}

한국에서의 이슈의 정치화나 논쟁의 정도를 고려해 볼때, 한국의 농어촌 개발(rural development)은 산업화 연구에 비해 현저히 취약한 분야이다. 특히 연구의 미약함은 해방 당시 농 업에 절대적으로 의존하고 있던 국가였다는 점을 고려할 때 더욱 놀라운 사실이다. 1940년대 와 1950 년대의 경작자에 토지를 분배한 농지개혁, 비료, 관개 사업, 새로운 종자의 보급 등에 도 불구하고, 농촌의 생활수준은 1960 년대 후반까지 크게 개선되지 못하였다. 아직 그 실질적 기여가 어느 정도였는지, 다른 요인은 없었는지에 대해서는 경험적 연구가 더 필요한 상황이 지만, 1970 년대초에 시작된 새마을 운동은 경제적 - 사회적 측면에서 농촌의 생활개선에 기여하 였다. 프로젝트에 참가한 Michael Douglass의 논문(The Saemaul Undong in Historical Perspective and in the Contemporary World)은 물질적, 인적 자원을 농어촌 경제사회 개발 을 위해 효과적으로 동원하고 농촌 지역에서의 빈곤과 불평등 정도를 개선한 전국 단위의 새 마을 운동을 농촌 개발 전략의 맥락에서 분석하였다. 그에 따르면, 해방이후 지속적으로 토지 개혁, 관개 사업, 비료보조금 등의 농촌 개발 정책이 이루어졌고, 이러한 정책들이 새마을 운 동, 보다 넓은 의미에서 농촌 개발 성공의 주요한 요인이 되었다. 특히 Michael Douglass는 새마을 운동 전과 새마을 운동 시기에 도시지역의 잉여가 농촌지역으로 옮겨지는 다양한 형태 의 농업 보조금을 매개로 한 재분배의 메커니즘이 새마을 운동의 성공요인이었음을 강조하고 있다. 한국 정부와 한국의 시민사회가 개발도상국에 다양한 형태의 새마을 운동 프로젝트를 전파하고 장려하는 현실을 고려할 때, 이 논문이 던지는 메시지는 주목할 만하다. 즉, 새마을 운동 혹은 보다 넓은 의미에서 농촌의 개발은 장기적인 시각과 포괄적 관점으로 이해해야 한 다는 것이다. 


\section{아. 개발의 이면}

1980년대 후반까지 한국의 급속한 경제성장과 사회개발 과정에서 민주주의가 부재했다는 것은 모든 이가 동의하는 것이다. 해방 후 약 30 년간, 거의 모든 시기에 선거는 존재했지만 자유민주주의의 근간 중의 하나라고 할 수 있는 표현과 반대의 자유는 존재하지 않았다. 권위 주의 정권하에서의 선거란 국민이 정치에 참가하는 기제라기보다는 권위주의 정부가 자신에 대한 국민의 지지를 측정하는 도구에 지나지 않는다고 볼 수 있다. 실제로 선거제도가 권력을 바꾸는 도구는 될 수 없다고 하더라도 정부에 대한 지지도의 변화를 측정하는 도구나 정부로 하여금 사회정책을 도입하게 하는 도구가 될 수는 있다. 한국의 경우에도 박정희 정부 시절 선거는 유권자의 대다수가 살고 있는 농촌 지역을 겨냥한 각종 정책, 즉 곡가 정책을 통한 농 업 보조금 등을 도입하고 유지하게 하는 기제로 작동하였다. 선거의 이러한 기능은 1970년대 초 완전히 사라지게 되고, 정부는 1987년까지 무소불위의 권력을 갖게 되었다. 이러한 민주주 의의 부재, 그렇지만 경제사회정책의 시행, 경제위기에 대한 대응 등으로 경제 사회발전을 이 뤄나간것은 “좋은 거버넌스(good governance)"보다는 이른바 “적당히 좋은 거버넌스(good enough governance)"의 이론적 실천적 적실성을 높일지도 모른다는 것을 시사하기도 한다 (Grindle, 2007). “좋은 거버넌스(Good governance)"는 대부분의 경우, 특정한 제도의 규칙, 과정, 기준 등에 있어서 비맥락적인 원칙에 근거한 것이고, 원조공여국이나 기관이 제시하는 기준인 경우가 많다. 박정희 정부의 거버넌스가 지금의 기준으로 얼마나 좋은 거버넌스였는 가는 경험적으로는 검증이 필요한 사안이나, 얼마나 실효성이 있었는가에 대해서는 긍정적이 라 할 것이다. 적당히 좋은 거버넌스로서의 한국의 경험 역시 더욱 심도있는 연구가 필요할 것이다.

민주주의의 부재 이외에도, 한국의 개발과정에서 큰 부족을 보이는 분야는 젠더 평등과 환 경이라 할 것이다. 이 프로젝트의 이진옥의 논문(Effective but Uneven)은 경제 활동 인구와

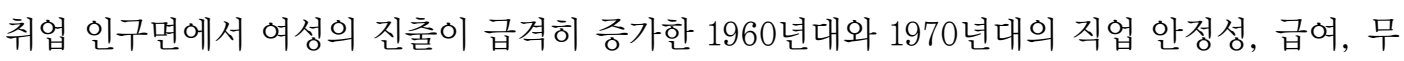
급 돌봄 노동을 분석하여 이 시기의 젠더 불평등을 조명했다. 특히 이진옥은 권위주의 체제의 경제 사회 정책의 틀을 만드는데 결정적인 역할을 한 모성적 규범 즉 전통과 근대의 가치 모두

를 체화하는 '현모양처'로 재정의되어 경제 발전을 위해 활용된 이데올로기적 기제에 초점을 맞추었다. 이러한 모성적 규범은 직업 훈련 프로그램이나 병역 의무와 긴밀하게 상호 작동하 는 기업 복지 체제와 같은 남성 편향적 정부 정책들과 결합하여 생산과 재생산 영역 모두에서 젠더 불평등을 지속시키는 구조를 만들었다. 이러한 요소들로 인해 사적 영역과 공적 영역 사 
이의 성별 분리와 재생산과 생산 사이의 허구적 구분은 강화되고 한국 발전 과정에서 사회적 재생산의 비용은 여성에게 전가되었다는 것이다.

Manoha Pawar와 허태욱의 공저 논문(Korean Responses to Environmental Challenges: Origins, Drivers and Impacts of Green Growth on Development)은 한국 개발경험의 이해 에 큰 기여를 했다고 볼 수 있는데, 이는 지금까지 한국 개발 경험 설명에서 상대적으로 주변 화 된 환경이슈를 집중적으로 분석하였기 때문이다. 저자들은 최근까지도 전형적인 환경 오염 국가로 취급되던 한국의 산업화과정에서 환경정책의 발전과정을 추적하였다. 논문이 보여주고 있는 것처럼, 한국의 산업화과정이 “환경정책 전무”의 상황에서 진행된 것은 아니었다. 1960 년대 이후, 산업화로 인한 환경오염에 대한 정책들이 수립되었다. 1960년대 이후 약 30년간에 걸친 환경 정책의 큰 특징 중의 하나는 환경문제의 의제화와 환경정책의 수립 모두 전형적인 하향식의 방식으로 이루어졌다는 것이다. 이런 환경 정책틀의 핵심은 인간을 자연으로부터 분 리, 소외시키는 징벌적 체계였다. 이러한 경향은 참여적 민주주의의 핵심이라고 할 수 있는 공 론이 부재하였다는 것과 긴밀히 연결되어 있다. 이러한 상황은 1990 년대까지 지속되었다. 해 방 후부터 최근까지의 환경 정책의 발전을 조망하며, Pawar와 허태욱은 환경정책의 결정과정 에 있어서의 민주주의, 특히 열린 자유토론의 중요성을 강조한다. 어떤 정책의 결과가 불확실 하고 그 애매함의 정도가 높을수록 모든 정책 관계자들이 참여하는 열린 자유토론의 존재가 중요해진다는 것이다.

\section{자. 한국의 경험으로부터 배운다는 것}

Thandika Mkandawire가 자신의 논문에서 강조하고 있는 것처럼 과거로부터 배운다는 것, 특히 특정 시기, 특정 조건 하에서의 한 국가의 경험으로부터 배운다는 것은 결코 쉬운 일이 아니다. 이를 위해서는 역사를 왜곡하는 다양한 요소들을 고려해야하고 걸러내야 하기 때문 이다. 때로는 어떻게 현재의 이데올로기적 투쟁이 과거의 경험을 유용하는가를 주목해야하며 때로는 어떤 성공적인 개발경험이라도, 존재하였던 시행착오를 잊게 만드는 요소들에 의해 윤색된다는 것에 주의해야한다. 경험을 공유하려는 국가가 자신의 경험을 공유하려는 의지가 있는지, 그러한 역량이 있는지, 혹은 배우려는 국가가 의지가 있는지, 배울 능력이 있는지 살 펴볼 필요도 있다. 실제로는 우연적 관계임에도 불구하고 논리적 필연성을 들이대고 인과적 관계로 해석하려고 하는 구조주의적 경향을 조심할 필요도 있다. 이 구조주의적 경향은 특히 나 많은 문제를 낳는데, 이러한 경향이 "모든 좋은 것은 함께 존재한다"라는 스토리를 만들어 
내기 때문이다. 대표적인 예가 아시아의 성장 기적을 우리가 생각하기에 좋은 것이라고 생 각하는 모든 요소들(예를 들면, 투명성, 책무성, 자율성, 반부패, 관료적 효율성, 노동의 유 연성, 내재적 국가-사회 관계, 유연성 등등)의 결과라고 해석하는 것이다. Thandika Mkandawire는 특히 그의 논문에서 아시아의 경험이 색다른 질문을 제기하는데 더욱 유용할 지도 모른다고 주장한다. 즉, '언제, 왜 높은 경제 성장이 다양한 형태의 악조건(부패, 관료적 경직성, 권위주의, 족벌경영, 비투명성 등등)과 공존하며 성취될 수 있었는가' 이다. 또한 이 러한 아시아 발전지향적 국가의 악조건 중 어떤 것들이 우연한 것이었으며 이러한 악조건 속 에서 어떤 제도와 기구가 개발 과제를 달성하기 위해 만들어졌고 결국 과제를 성취했는가 역 시 질문할 수 있다는 것이다. 이러한 악조건들을 먼저 제거하는 것이 개발의 선결조건이라고 생각하는 이들과, 지금도 이러한 악조건들과 함께 개발 과제를 수행해 나가야하는 이들과의 사이에는 그 개발전략에 있어서 큰 인식의 차가 존재한다고 할 수 있다. 결국, 개발논의에 있 어서 맥락의존성(context-specificity)과 교훈의 다른 국가에의 적용 적절성(the relevance of the lessons to other countries)의 문제는 이러한 상이한 견해간의 토론에 부쳐져야 하는 것일 것이다.

\section{2. 맺음말을 대신하여}

개발논의에서 모델이란, 정의상 그 모델이 나타내고자 하는 사회라는 실체가 가진 복잡성을 대표하는 것이라 볼 수 있다. 이러한 모델화는 우리로 하여금 그 모델로부터 도출되는 교훈이 비맥락적일 수 있다는 위험을 즉각 인식하게 만든다. 이는 또한 실제의 역사적 경험과 이론적 모델을 혼동해서는 안된다는 경고를 주기도 한다. 모델이 실체를 지나치게 단순화시키면 안될 뿐더러 만약 특수한 정치- 경제적 맥락을 대표하여 추상화되면 최악의 수준이 되기도 한다. 이러한 추상화의 한 예가 한국을 포함한 동아시아의 경험을 신자유주의 모델로 추상화하는 것 이다. 이러한 모델화가 더욱 문제가 되는 것은 이런 모델이 대부분의 경우 후발주자들이 더 관 심을 가질만한 요소들을 빼놓을 수 있다는 것이다. 서구 선진국의 복지국가의 모델화, 추상화 가 이러한 경우의 대표적 예일 것이다. 즉 서구 선진국의 복지국가 발전에서 개발적 측면, 전 환을 촉발하는 측면은 추상화 속에서 사라지고, 보장의 측면, 재분배의 측면만 모델화되었던 것이다. 이러한 추상화, 모델화를 통해 개발도상국에서 복지국가란 생산이나 개발이 어느정도 수준에 이르렀을때에야 가능하다는 결론이 도출되었던 것이다. 
선진국으로부터 배운 특정의 정책이 정책 수입국에서 비슷한 결과를 초래한다는 보장은 어 디에도 없다. 그런면에서 이 프로젝트의 교훈 도출 역시, 한국이 그들의 개발과정에서 무엇을 했는가를 분석하는 것에 집중하였다. 공여국으로서 무엇을 하라고 말하는 것이 아니라 수원국 으로서 무엇을 했다는 것이 후발주자에게 더욱 필요한 교훈이기 때문이다. 


\section{참고문헌}

Amsden, A. (1992) Asia's Next Giant: South Korea and Late Industrialization, Oxford University Press, Oxford.

Balassa, B. (1991) Economic Policies in the Pacific Area Developing Countries, New York University Press, New York.

Chang, H. 2004. The role of social policy in economic development: Some theoretical reflections and lessons from Asia. In SocialPolicyinDevelopmentContext, editedbyT.Mkandawire.London : Palgravemacmillan.

Chua, B. H. (2005) Welfare Developmentalism: Singapore and Malaysia, In Transforming the Developmental Welfare State in East Asia(Ed, Kwon, H.) Macmillan Palgrave, New York.

Cumings, B. (1987) The Origins and Development of the Northeast Asian Political Economy: Industrial Sectors, Product Cycles, and Political Consequences, In The Political Economy of the New Asian Industrialization(Ed, Deyo, F., C.) Cornell University Press, Ithaca, New York.

Cumings, Bruce. 1987. The Origins and Development of the Northeast Asian Political Economy : Industrial Sectors, Product Cycles, and Political Consequences. In The Political Economy of the New Asian Industrialization, edited by F. Deyo, C. Ithaca, NewYork : Cornell University Press.

Deyo, F., C. (1987) Introduction, In The Political Economy of the New Asian Industrialization(Ed, Deyo, F., C.) Cornell University Press, Ithaca, New York.

Doucouliagos, H. and Paldam, M. (2009) The Aid Effectiveness Literature: The Sad Results of 40 Years of Research, In Cambridge Working Papers in EconomicsUniversity of Cambridge, Cambridge.

Esping-Andersen (1990) The Three Worlds of Welfare Capitalism, Polity Press, Cambridge. Esping-Andersen (1990) The Three Worlds of Welfare Capitalism, Polity Press, Cambridge. Estevez-Abe, M. (2008) Welfare and Capitalism in Postwar Japan, Cambridge University Press, New York.

Fine, B. (2011) Locating the Developmental State and Industrial and Social Policy after the Crisis, In The Least Developed Countries Report 2011(Ed, UNCTAD) UNCTAD, Geneva.

Fraser, A. and Whitfield, L. (2009) Understanding Contemporary Aid Relationship, In The Politics of Aid(Ed, Whitfield, L.) Oxford University Press, Oxford and New York. 
Fritz, V. and Menocal, A. R. (2007) Developmental States in the New Millenium : Concepts and Challenges for a New Aid Agenda, Develoment Policy Review, 25, 531-552.

Goodman, R., White, G. and Kwon, H. (1998) The East Asian Welfare Model, Routledge, London and New York.

Grindle, M. (2007) Good Enough Governance Revisited, Development Policy Review, 27, $553-574$.

Immergut, E., M. (1992) The Rule of the Game: The Logic of Health Policy-Making in France, Switzerland, and Sweden, In Structuring Politics: Historical Institutionalism in Comparative Analysis(Eds, Steinmo, S., Thelen, K. and Longstreth, F.) Cambridge University Press, Cambridge.

Johnson, C. (1987) Political Institutions and Economic Performance: The Government-business Relationship in Japan, South Korea, and Taiwan, In The Political Economy of the New Asian Industrialization(Ed, Deyo, F., C.) Cornell University Press, Ithaka, New York.

Kim, E. M. (1997) Big Business, Strong State: Collusion and Conflict in South Korean Development, 1960-1990, State University of New York, New York.

Kindornay, S. (2011) From Aid to Development Effectiveness: A Working Paper, The North-South Institute, Toronto.

Koen, M. (1977) Korean Phoenix : A Nation from the Ashes, Prentice-Hall, Englewood Cliffs.

Kohli, A. 2004. State-Directed Development : Political Powerand Industrialization in the Global Pheriphery. NewYork : Cambridge University Press.

Krueger, A. O. (1982) The Developmental Role of the Foreign Sector and Aid, Council on East Asian Studies, Harvard University, Cambridge, MA, and London.

Krueger, A. O., Michalopoulos, C. and Ruttan, V. W. (1989) Aid and Development, The Johns Hopkins University Press, Baltimore and London.

Krueger, A., O. (1990) Asian Trade and Growth Lessons, The American Economic Review, $80,108-112$.

Kwon, H. (1999) The Welfare State in Korea, Macmillan Press Ltd, London.

Kwon, H. (2005) An Overview of the Study: The Developmental Welfare State and Policy Reforms in East Asia, In Transforming the Developmental Welfare State in East Asia(Ed, Kwon, H.) Palgrave Macmillan, New York.

Kwon, H. and Yi, I. (2010) Economic Development and Poverty Reduction in Korea : Governing Multifunctional Institutions, Development and Change, 40, 769-792. 
Lewis, J. P. (1955) Reconstruction and Development in South Korea, National Planning Association, Washington D.C.

Little, I. M. D. (1982) Economic Development, Basic Books, New York.

Mares, I. (2001) Firms and the Welfare State: When, Why, and How Does Social Policy Matter to Employers?, In Varieties of Capitalism: The Institutional Foundations of Comparative Advantage(Eds, Hall, P., A. and Soskice, D.) Oxford University Press, Oxford.

Mkandawire, T. (2004) Social Policy in a Development Context : Introduction, In Social Policy in a Development Context(Ed, Mkandawire, T.) Palgrave Macmillan, New York.

Przeworski, A., Alvarez, M., E., Cheibub, J. A. and Limongi, F. (2000) Democracy and Development, Cambridge University Press, Cambridge and New York.

Przeworski, A., Michael Alvarez, E., Jose Antonie Cheibub, and Fernando Limongi. 2000. DemocracyandDevelopment. CambridgeandNewYork : CambridgeUniversityPress.

Raghuram, R. and Subramanian, A. (2009) Aid, Dutch Disease, and Manufacturing Growth, In Working PaperCenter for Global Development, Washington, D.C.

Robert Cassen and Associates (1994) Does Aid Work, Clarendon Press, Oxford.

Sen, A. (2010) The Idea of Justice, Penguin Books, London and New York.

Sen, A. 1999. DevelopmentasFreedom. OxfordandNewYork : OxfordUniversityPress.

Thandika, M. (2009) Institutional Monocropping and Monotasking in Africa, In Democracy, Governance and Well-Being Programme Paper(Ed, UNRISD) UNRISD, Geneva.

The World Bank (1993) The Asian Miracle: Economic Growth and Public Policy, The World Bank, New York.

Wade, R. (1990) Governing the Market, Princeton University Press, Princeton, New Jersey. Wilensky, H. L. and Lebeaux, C. N. (1965) Industrial Society and Social Welfare, The Free Press, New York.

World Bank (1997) World Development Report: The State in a Changing World, World Bank, Washington D.C.

Wornonoff, J. (1983) Korea's Economy: Man-made Miracle, Si-sa-yong-o-sa Publishers, Seoul and Oregon.

Yi, I. (2007) The Politics of Occupational Welfare in Korea, Hana Shyoin, Fukuoka. 


\section{부록 1. 목차}

\section{Contents}

Overview: Learning from Developmental Success (Ilcheong Yi, UNRISD, and Thandika Mkandawire, London School of Economics)

\section{PART I}

Lessons from the Social Policy and Development of South Korea : An Interrogation (Thandika Mkandawire, London School of Economics)

The Korean Experience and the $21^{\text {st }}$ Century Transition to a Capability Enhancing Developmental State(Peter Evans, University of California, Berkeley)

Securing the Home Market: A New Approach to Korean Development (Alice Amsden, Massachusetts Institute of Technology)

\section{PART II}

Institutional Linkages between Social Protection Measures and Industrialisation in Korea (Jooha Lee, Donguk University)

Development of Transformative Social Policy in Korea : Lessons from the Korean Experience (Moo-Kwon Chung, Yonsei University)

The Saemaul Undong in Historical Perspective and in the Contemporary World (Mike Douglass, National University of Singapore)

How Could Enhancement of Education and Health Contribute to Economic Growth in South Korea? ( Ilcheong Yi, UNRISD)

\section{PART III}

Effective Aid and Development Cooperation in South Korea (Ilcheong Yi, UNRISD, Olive Cocoman, UNRISD, Youah Chung, KOICA, Hyunjoo Rhee, KOICA)

Learning through Localizing International Transfers: South Korea's Development Experiences (Taekyoon Kim, Seoul National University) 
The South Korean Developmental Alliance between

Business, Labour and Government (Eun Mee Kim. Ewha Womans University)

\section{PART IV}

Change and Continuity in Social Policy Responses to Economic Crises in South Korea : 1979-81 vs. 1997-98 (Jae-jin Yang, Yonsei University)

Effective but Uneven : Korean Development from a Gender Perspective (Jinock Lee, Seogang University)

Korean Responses to Environmental Challenges : Origins, Drivers and Impacts of Green Growth on Development (Manohar Pawar, Charles Stuart University and Taewook Huh, DongA University) 